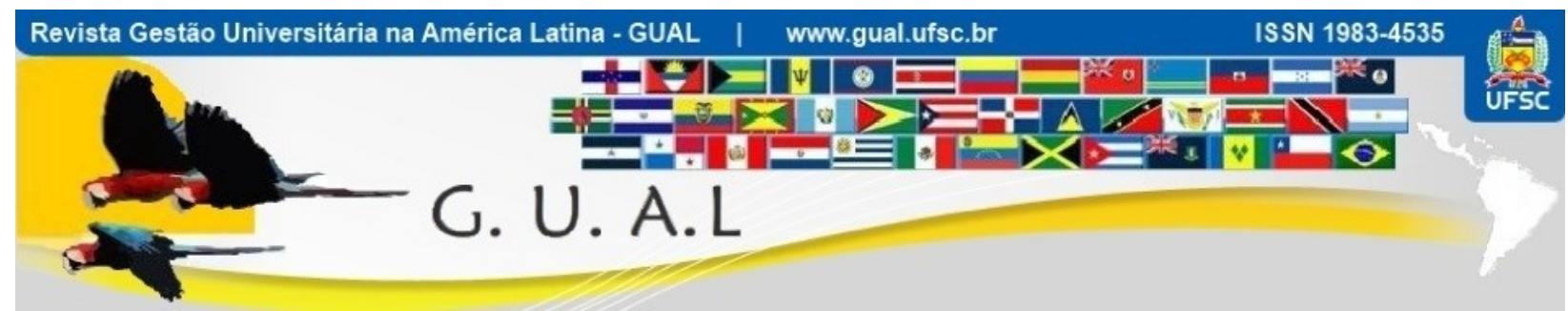

DOI: http://dx.doi.org/10.5007/1983-4535.2018v11n3p1

\title{
DESEMPENHO ACADÊMICO VERSUS RENDA: ANÁLISE COMPARATIVA REALIZADA COM EGRESSOS DE UM CURSO DE ADMINISTRAÇÃO
}

\section{ACADEMIC PERFORMANCE VS. FAMILY INCOME: A SURVEY WITH THE GRADUATES OF A BUSINESS ADMINISTRATION COURSE}

André Ferreira, Doutor Universidade Federal Fluminense - UFF andre.ferreira10@gmail.com

Caroline Salles Abranches, Especialista Universidade Federal Fluminense - UFF caroline.abranches@gmail.com

Recebido em 09/fevereiro/2017

Aprovado em 03/agosto/2018

Sistema de Avaliação: Double Blind Review

Esta obra está sob uma Licença Creative Commons Atribuição-Uso. 


\title{
RESUMO
}

O objetivo desta pesquisa foi verificar se há correlação entre o desempenho acadêmico e a renda de alunos egressos de um curso de administração. O método utilizado foi o levantamento (survey) e a pesquisa de campo foi realizada na Faculdade de Ciências Sociais Aplicadas do Sul de Minas (FACESM), com todos os formados em Administração no período de 2007 a 2012. O número total de questionários enviados foi de 270, sendo que 75 egressos responderam a pesquisa. Os principais resultados indicam que, no âmbito desta amostra, não foi encontrada uma correlação direta entre o desempenho acadêmico e a renda dos egressos. Entretanto, foi possível verificar que a incidência de alunos com maior renda é mais elevada com os egressos que tiveram CR (coeficiente de rendimento) maiores. Conclui-se, no âmbito desta amostra, que apesar de não haver uma correlação direta entre CR e renda, os egressos que possuem os CR's mais elevados têm maiores possibilidades de receber rendimentos mais elevados.

Palavras chave: Desempenho Acadêmico. Desempenho Profissional. Egresso.

\begin{abstract}
The main objective of this research was to verify the correlation between academic performance and the income of graduates. The survey was applied in a private college in southern Minas Gerais (Faculdade de Ciências Sociais Aplicadas do Sul de Minas FACESM). The method used was a survey and the data collection were document analysis and questionnaires to former students by e-mail. Was sent 270 questionnaires, and 75 returned. Regarding the results of the questionnaire proposed to undergraduates, which has been found is that they evaluate positively the received college formation. As the current professional situation of administrators was found that $82 \%$ of graduates work in their area of training. Continuing education was performed by $86 \%$ of the sample surveyed. Regarding the possible existence of correlation between academic performance and the income, a direct correlation between these variables was not found. However, we found that the incidence of students with higher income is higher with the graduates who had CR higher. It can be concluded within this sample, although there is a direct correlation between CR and professional success, students who have the highest CR's are more likely to receive higher yields.
\end{abstract}

Keywords: Academic Performance. Performance Professional. Graduates. 


\section{DESEMPENHO ACADÊMICO VERSUS RENDA: ANÁLISE COMPARATIVA REALIZADA COM EGRESSOS DE UM CURSO DE ADMINISTRAÇÃO \\ DOI: http://dx.doi.org/10.5007/1983-4535.2018v11n3p1}

\section{INTRODUÇÃO}

Apesar de as diretrizes curriculares do curso de graduação em Administração apresentarem um equilíbrio no tripé conhecimento, habilidade e atitude na formação das competências de seus egressos (MEC, 2003), a realidade aponta que os aspectos relacionados ao conhecimento são os que recebem maior ênfase na formação do futuro profissional de Administração. Assim, a graduação do administrador é caracterizada pela predominância da transmissão de conceitos e teorias, com menor ênfase para as atividades que desenvolvem as habilidades e atitudes dos discentes em sua vida acadêmica.

Esta realidade do egresso de administração apresenta um campo de estudo relevante para se tentar compreender o impacto que o conhecimento tem sobre os rendimentos dos egressos de cursos de graduação. A ênfase na transmissão de conhecimentos, que hoje caracteriza os cursos de graduação em administração, facilita identificar se a aquisição de conhecimentos teóricos se reverte em um diferencial financeiro para os egressos no mercado.

Neste contexto, a questão que se coloca é: alunos que se destacam no meio acadêmico, com avaliações acima da média, também se destacam no mercado? Ou seja, a aquisição de conhecimento na universidade se reflete como um diferencial nos rendimentos do egresso. Nesta pesquisa, o foco são egressos do curso de Administração da Faculdade de Ciências Sociais Aplicadas do Sul de Minas (FACESM) localizada na região sul de Mina Gerais.

Para atingir este objetivo foi replicada, de forma adaptada, a pesquisa desenvolvida por Ferreira e Crisóstomo (2011), que analisou a correlação entre desempenho acadêmico e os rendimentos dos egressos de um curso de Engenharia Metalúrgica.

\section{REFERENCIAL TEÓRICO}

\subsection{CONSTRUÇÃO DE COMPETÊNCIAS DENTRO DA VIDA ACADÊMICA}

O Conselho Federal de Administração (CFA), bem como as comissões do Conselho Nacional da Educação (CNE) têm apresentado algumas diretrizes para que as universidades contemplem em seus projetos pedagógicos uma realidade alinhada às necessidades das organizações.

Uma destas diretrizes é o enfoque na formação baseada em competências, que tem suas raízes na década de 1920, nos Estados Unidos, embora só tenha ganhado destaque a partir da década de 1960, quando foi retomado o debate clássico do distanciamento entre o ensino acadêmico e a realidade da vida e do trabalho. As transformações necessárias à 


\section{DESEMPENHO ACADÊMICO VERSUS RENDA: ANÁLISE COMPARATIVA REALIZADA COM EGRESSOS DE UM CURSO DE ADMINISTRAÇÃO \\ DOI: http://dx.doi.org/10.5007/1983-4535.2018v11n3p1}

adequação do ensino a essa nova realidade vêm sendo discutidas em nível internacional. E é no bojo desse debate que a noção de competências ocupa espaço privilegiado, tendo sido eleita como perspectiva pedagógica para a implementação da reforma educacional em diversos países, entre os quais se inclui o Brasil (NUNES, 2009).

O desenvolvimento de competências como padrão de articulação entre conhecimento e inteligência pessoal, ganha espaço nas instituições educacionais por exigências das diretrizes e bases educacionais nacional e se torna o eixo dos processos de ensino e aprendizagem (ANDRADE E AMBONI, 2004).

Neste contexto, em julho de 2005, o Conselho Nacional da Educação, por meio da Resolução $\mathrm{N}^{0}$ 4/2005 (BRASIL, 2005), determinou as diretrizes para a reformulação do ensino superior de graduação em administração. Dentre as proposições de mudanças estão a ênfase na formação ética, o incentivo à criatividade, o estímulo espírito inovador, o desenvolvimento de competências e habilidades que assegurem competitividade frente às transformações econômicas e sociais, o desenvolvimento do espírito crítico e conjugação do saber pensar com o saber fazer e intervir. A partir destes elementos, o objetivo era de que os egressos do curso de administração não sairiam das universidades apenas com conhecimento, mas também como habilidades, atitudes e valores.

De acordo com Andrade e Amboni (2004) os projetos pedagógicos dos cursos de administração devem contemplar em sua organização curricular conteúdos que possibilite inter-relações com a realidade local e regional, em sintonia com a nacional e internacional, segundo uma perspectiva histórica e contextualizada de sua aplicabilidade no âmbito das organizações e do meio pela utilização de tecnologias inovadoras.

Apesar destes esforços, observa-se que quando se analisa o tripé da competência (conhecimento, habilidade e atitude) o ensino da administração ainda está fortemente centrado na transmissão do conhecimento. Um dos desafios apontados por Andrade e Amboni (2004) está na adoção de estratégias de ensino diversificadas que mobilizem menos a memória e mais o raciocínio e outras competências cognitivas superiores, que fortaleçam a interação entre aluno e professor e aluno para uma construção coletiva do conhecimento.

Alunos adquirem conhecimentos sobre negócios, porém não é certo que eles adquirem habilidades de fazer negócios. Mintzberg e Lampel (2001) consideram que não existe maneira de recriarem negócios verdadeiros dentro de uma sala de aula, porém estudo de caso é uma maneira onde estudantes sem experiências recebem uma apresentação de vinte paginas e 


\section{DESEMPENHO ACADÊMICO VERSUS RENDA: ANÁLISE COMPARATIVA REALIZADA COM EGRESSOS DE UM CURSO DE ADMINISTRAÇÃO \\ DOI: http://dx.doi.org/10.5007/1983-4535.2018v11n3p1}

apresenta a sua análise. Não se pode dispensar totalmente abordagem cientifica, porém ela por si só não é totalmente suficiente para ajudar no ensino de gestão.

Schon $(1983,1987)$ enfatizou que a diferença da teoria é que na prática há a habilidade de transformar situações incertas em certas. A arte profissional, então, requer transcender as regras e os planos da racionalidade técnica para 'pensar na ação’ (Bailey et al 1997).

Tem-se discutido bastante sobre a formação dos administradores diante do que o mercado exige hoje. Para Closs et al (2006), há cada vez mais estudos teóricos que enfatizam uma necessidade de atualização ou mudança do ensino-aprendizagem na formação de gestão, mas há evidencias que poucas mudanças venham sido observadas de fato na pratica de ensino. Observa-se uma crítica sobre a adequação dos projetos das Instituto de Educação Superior (IES) de graduação em administração, diante do que a demanda do mercado exige dos egressos.

\subsection{DESEMPENHO ACADÊMICO E DESEMPENHO PROFISSIONAL EM UM CURSO ENGENHARIA METALÚRGICA}

Ferreira e Crisóstomo (2011) desenvolveram uma pesquisa que buscou verificar se há correlação entre o desempenho acadêmico e o desempenho profissional (mensurado através dos rendimentos salariais) dos alunos formados em engenharia metalúrgica no período de 2000 a 2005 na Escola de Engenharia Industrial Metalúrgica de Volta Redonda (EEIMVR), que tem seus resultados apresentados a seguir.

A pesquisa foi realizada junto aos formandos no período de 2000 a 2005 , perfazendo um total de 142 egressos, para os quais foram enviados os questionários eletrônicos, sendo que 44 retornaram. Os resultados mais relevantes da pesquisa indicam uma convergência de opiniões do Coordenador, Chefe de Departamento e Professor de engenharia metalúrgica no sentido de considerar que os alunos ingressam imaturos na universidade e que o Coeficiente de Rendimento (CR) dos alunos é uma indicação boa, mas o CR alto não é uma garantia de que o aluno terá um melhor desempenho profissional.

Em relação, aos resultados do questionário proposto aos egressos, o que se verificou é que os mesmos avaliam de maneira positiva a formação recebida da EEIMVR. Com esse questionário foi possível verificar a correlação entre o coeficiente de rendimento e a renda individual mensal dos engenheiros.

As faixas salariais foram divididas em até $\mathrm{R} \$ 2.000,00$, de $\mathrm{R} \$ 2.001,00$ a $\mathrm{R} \$ 4.000,00$, de $\mathrm{R} \$ 4.001,00$ a $\mathrm{R} \$ 6.000,00$ e acima de $\mathrm{R} \$ 6.000,00$. 


\section{DESEMPENHO ACADÊMICO VERSUS RENDA: ANÁLISE COMPARATIVA REALIZADA COM EGRESSOS DE UM CURSO DE ADMINISTRAÇÃO \\ DOI: http://dx.doi.org/10.5007/1983-4535.2018v11n3p1}

Não foi possível verificar uma correlação direta entre o CR e a renda dos egressos, uma vez que existem engenheiros que obtiveram notas menores que seis e obtêm salários superiores a R \$ 6.000,00 e por outro lado existem egressos com notas superiores a oito que estão ganhando entre R $\$ 2.000,00$ e R \$ 4.000,00.

Concluiu-se que com a amostra de 44 egressos de engenharia metalúrgica não se verificou qualquer correlação entre a renda, ou o cargo com o desempenho acadêmico. Todavia foi possível verificar que a incidência de alunos com salários acima de $\mathrm{R} \$ 6.000,00$ é maior com os egressos que tiveram notas (coeficiente de rendimento) maiores. Portanto é possível constatar que o desempenho acadêmico não é uma condição suficiente e necessária para o aluno ter um melhor desempenho profissional (medido pela renda), porém o aluno que obtiver melhor desempenho acadêmico (maior nota) terá maior probabilidade/possibilidade de ter o melhor sucesso profissional (maior renda).

\section{MÉTODO DE PESQUISA}

Esta pesquisa é de natureza aplicada, com uma abordagem qualitativa, pois há a obtenção de dados descritivos sobre egressos do curso de administração de empresas. É também, quantitativa, pois a pesquisa busca quantificar dados coletados, para identificar a relação entre o desempenho acadêmico dos alunos da graduação de administração e a faixa salarial dos mesmos no mercado de trabalho em dados numéricos.

A pesquisa é de caráter exploratório, para comprovar uma hipótese. Segundo Gil (2002) este tipo de pesquisa tem a finalidade de aprimorar ideias ou a descoberta de intuições. Seu planejamento é bastante flexível, possibilitando a consideração dos mais variados aspectos ao fato estudado. Quanto aos procedimentos técnicos foram utilizados análise bibliográfica, análise documental e levantamento.

A população da pesquisa corresponde a todos os alunos formados no curso de administração de empresas da Faculdade de Ciências Sociais Aplicadas do Sul de Minas (FACESM) entre 2007 e 2010. Foram enviados questionários para os 270 alunos formados neste período, sendo que 75 respondentes retornaram preenchidos, representando uma taxa retorno de $28 \%$.

Para a pesquisa junto aos egressos foi replicado o questionário adaptado de Ferreira e Crisóstomo (2011). O questionário foi enviado para os entrevistados por e-mail através do 
sistema "Google doc - formulário escrito". Foram utilizadas estatísticas descritivas simples para analisar os dados.

\section{RESULTADOS E DISCUSSÃO DOS RESULTADOS}

\subsection{CARACTERÍSTICAS DO CURSO DE ADMINISTRAÇÃO DA FACULDADE DE CIÊNCIAS SOCIAIS APLICADAS DO SUL DE MINAS}

A Faculdade de Ciências Sociais Aplicadas do Sul de Minas (FACESM) é um estabelecimento isolado de ensino superior, localizada no município de Itajubá e mantida pelo Centro Regional de Cultura - CEREC. Ela originou-se da Faculdade de Ciências Econômicas do Sul de Minas, criada em 1965 pela Sociedade Colégio de Itajubá.

Atualmente a FACESM possui três cursos de graduação: Ciências Econômicas, Ciências Contábeis e Administração. Em 1998, foi autorizado o Curso de Administração, pela Portaria Ministerial $n^{\circ} 229$, de 06/03/1998 (DOU de 10/03/1998) sendo reconhecido pela Portaria $n^{\circ} 3.121$ de 31/10/2003 (DOU de 04/11/2003).

A primeira grande mudança na grade do curso foi promovida em 2007 quando a duração do curso passou de cinco para quatro anos. Em 2009 houve nova alteração da grade curricular, objetivando uma maior aplicabilidade e atualização dos conteúdos, alinhando com as demandas do mercado.

A organização das disciplinas ao longo dos quatro anos considera a progressão do nível de maturidade do aluno e os pré-requisitos. No primeiro ano são desenvolvidos conhecimentos básicos buscando um nivelamento. $\mathrm{O}$ foco neste primeiro ano é o comportamento. O projeto interdisciplinar é o desenvolvimento de uma ideia de negócio que é exposto em uma feira de empreendedorismo organizado e desenvolvido pelos próprios alunos.

No segundo ano o foco são as operações, onde o conjunto de disciplinas gera a visão operacional de uma empresa. O projeto interdisciplinar neste ano é uma simulação empresarial envolvendo todas as operações de uma empresa fabricante de monitores de computadores. Depois do desenvolvimento é promovido uma feira onde acontece uma competição para identificar a empresa de melhor desempenho. Nesta oportunidade são convidados empresários, ex-alunos e professores que serão compradores e estarão negociando com as empresas fictícias. No terceiro ano o foco é o negócio, onde busca formar a visão de negócio. O projeto interdisciplinar é um projeto social que os alunos desenvolvem. Para atender as demandas sociais existentes na cidade de Itajubá e cidades circunvizinhas. O 


\section{DESEMPENHO ACADÊMICO VERSUS RENDA: ANÁLISE COMPARATIVA REALIZADA COM EGRESSOS DE UM CURSO DE ADMINISTRAÇÃO \\ DOI: http://dx.doi.org/10.5007/1983-4535.2018v11n3p1}

resultado da execução dos projetos são apresentados na Feira de empreendedorismo (a mesma do primeiro ano).

No quarto ano, a partir da visão existente até o terceiro ano (negócio), o foco é a inserção do negócio no cenário globalizado. Neste ano, o projeto desenvolvido é o trabalho de conclusão de curso (TCC), em que aluno desenvolve uma pesquisa bibliográfica e uma aplicação de um conceito, modelo ou teoria. O trabalho é supervisionado por um professor coordenador e orientado por um professor. Durante o desenvolvimento do curso, o aluno deve participar de 100 horas de atividades complementares (não incluídos na grade) que complementam a formação do administrador. Também faz parte da carga horária de formação o estagio supervisionado, que deverá ser em um ambiente empresarial com uma carga horária mínima de 300 horas.

\subsection{PERFIL DOS EGRESSOS}

A primeira parte do questionário foi composta por perguntas que permitiram verificar o perfil dos egressos do curso de administração. Da amostra, 41\% dos respondentes são do sexo masculino e 59\% feminino. Com referência ao tipo de escola frequentada no nível médio, $62 \%$, dos respondentes concluíram seu ensino médio em escolas públicas.

Ao se verificar a correlação entre a renda dos egressos em relação ao tipo de escola do ensino médio, não foi observada nenhuma diferença que apresentasse uma relação de causaefeito entre escola cursada no nível médio e renda atual (coeficiente de correlção $=0,1523$ ), conforme Gráfico 1.

Com referência ao tempo de formado e a renda do engresso, não foi identificado nenhum tipo de correlação, sendo que o coeficiente de correlação entre estas duas variáveis foi de apenas 0,12 conforme apresentado no Gráfico 2.

Quanto à experiência profissional, apenas $1 \%$ dos respoendetes tem experiência profissional menor do que um ano. A maior parte, $33 \%$ dos respondentes, tem acima de oito anos de experiencia profissional, seguindo de 5 a 8 anos, 30\%, 3 a 5 anos $21 \%$ e 1 a 3 anos, $13 \%$.

Também não correlação entre renda e tempo de experiência profissional, que apresentou um baixo coefeciente de correlção $(0,0412)$, conforme Gráfíco 3. 
Gráfico 1 Tipo de Escola x Renda

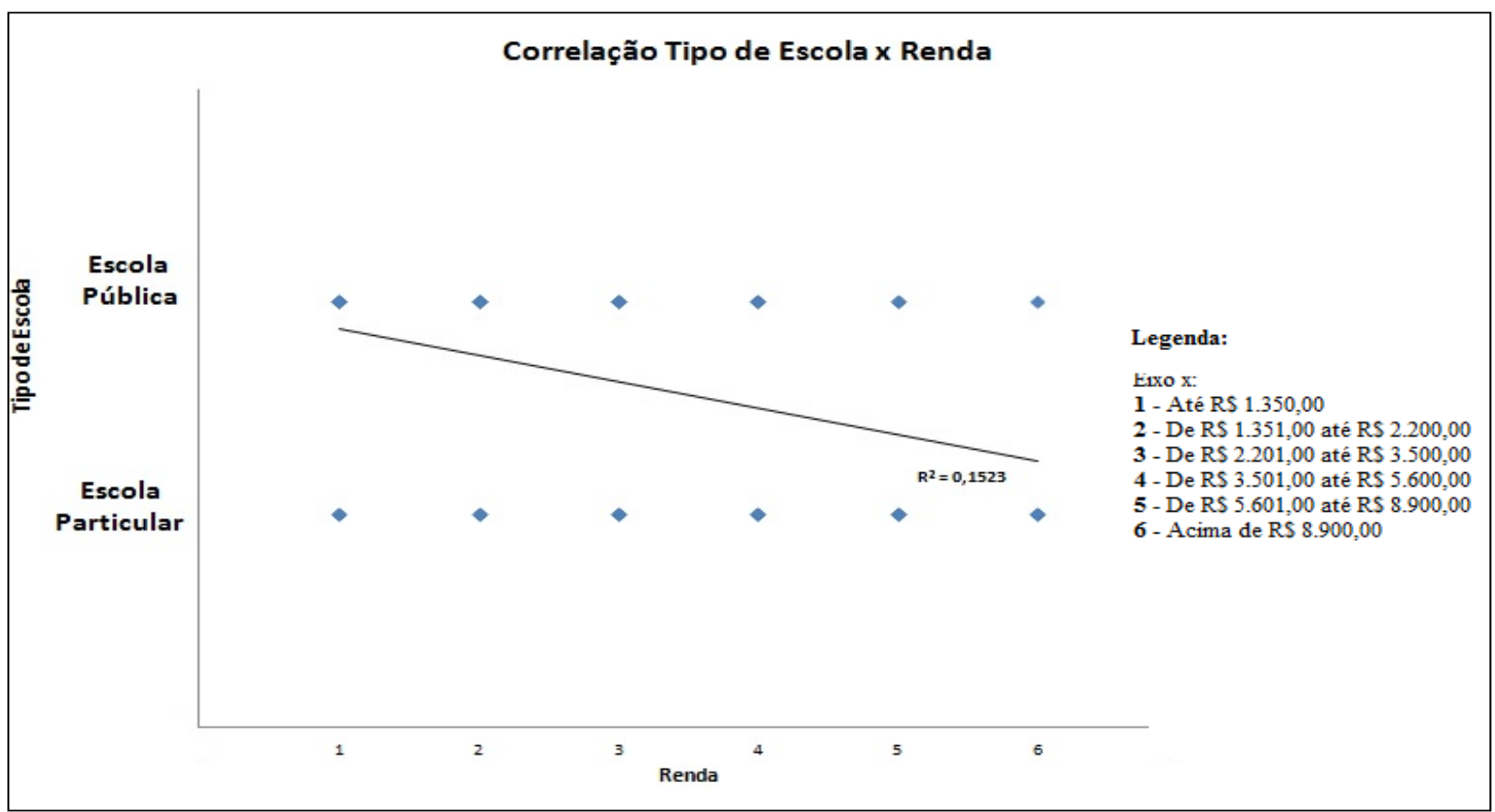

Fonte: Dados da Pesquisa

Gráfico 2 Renda x Conclusão de Curso

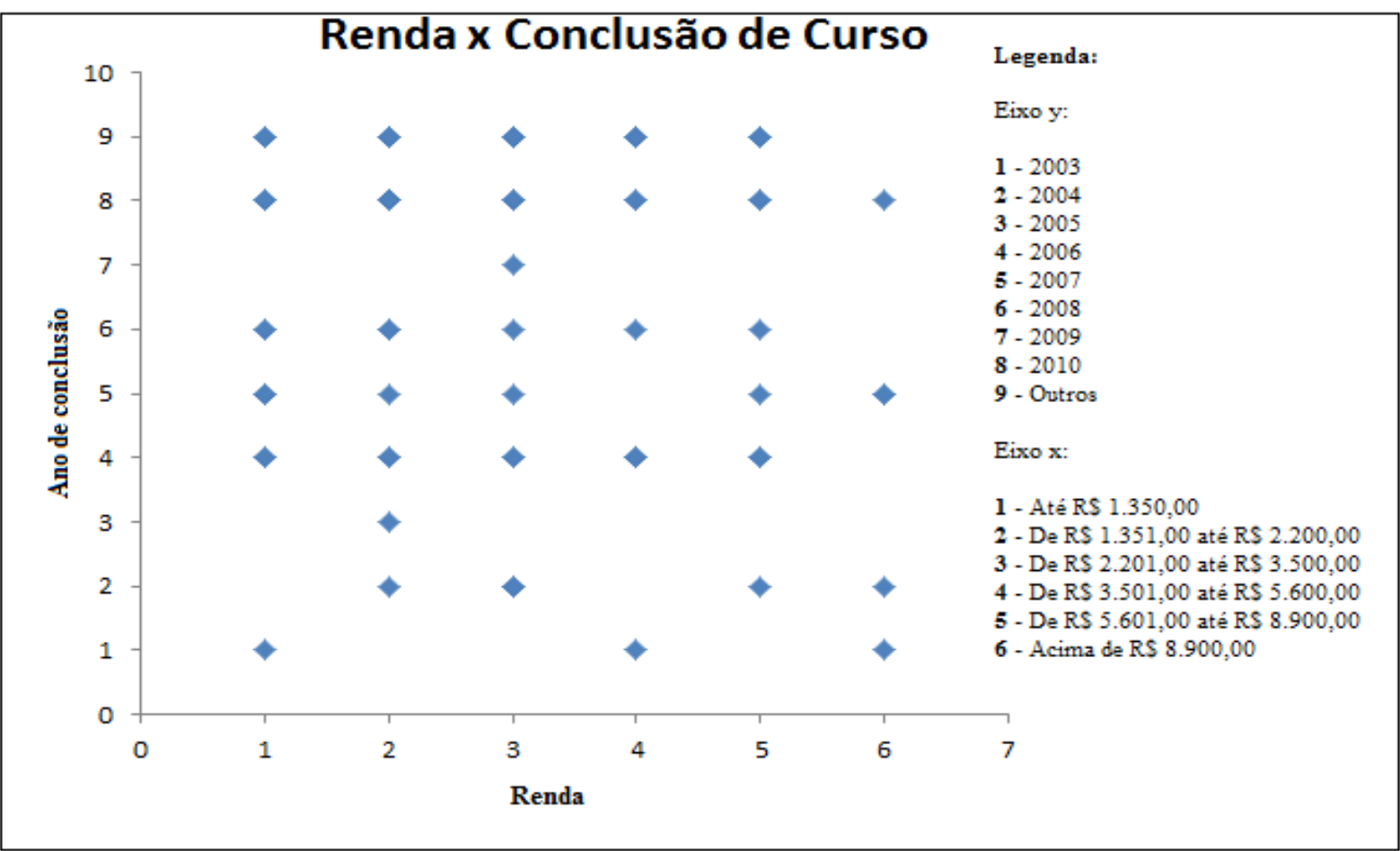

Fonte: Dados da Pesquisa 
Gráfico 3 Experiência Profissional x Renda

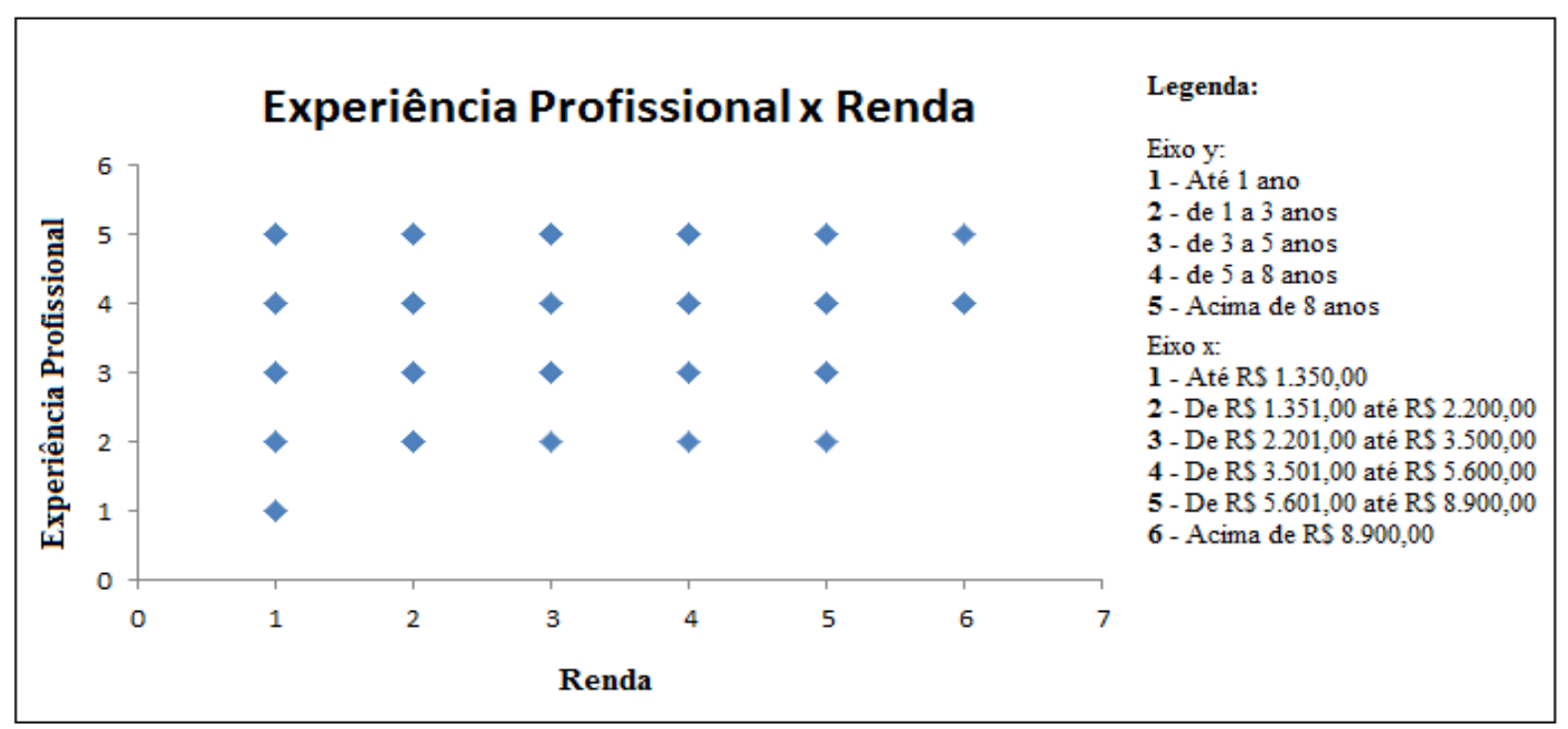

Fonte: Dados da Pesquisa

\subsection{AVALIAÇÃO DO CURSO}

Em um segundo momento os egressos responderam perguntas relacionadas ao curso. A avaliação do curso, na percepção dos egressos é apresentada no Gráfico 4:

Gráfico 4 Avaliação do Curso

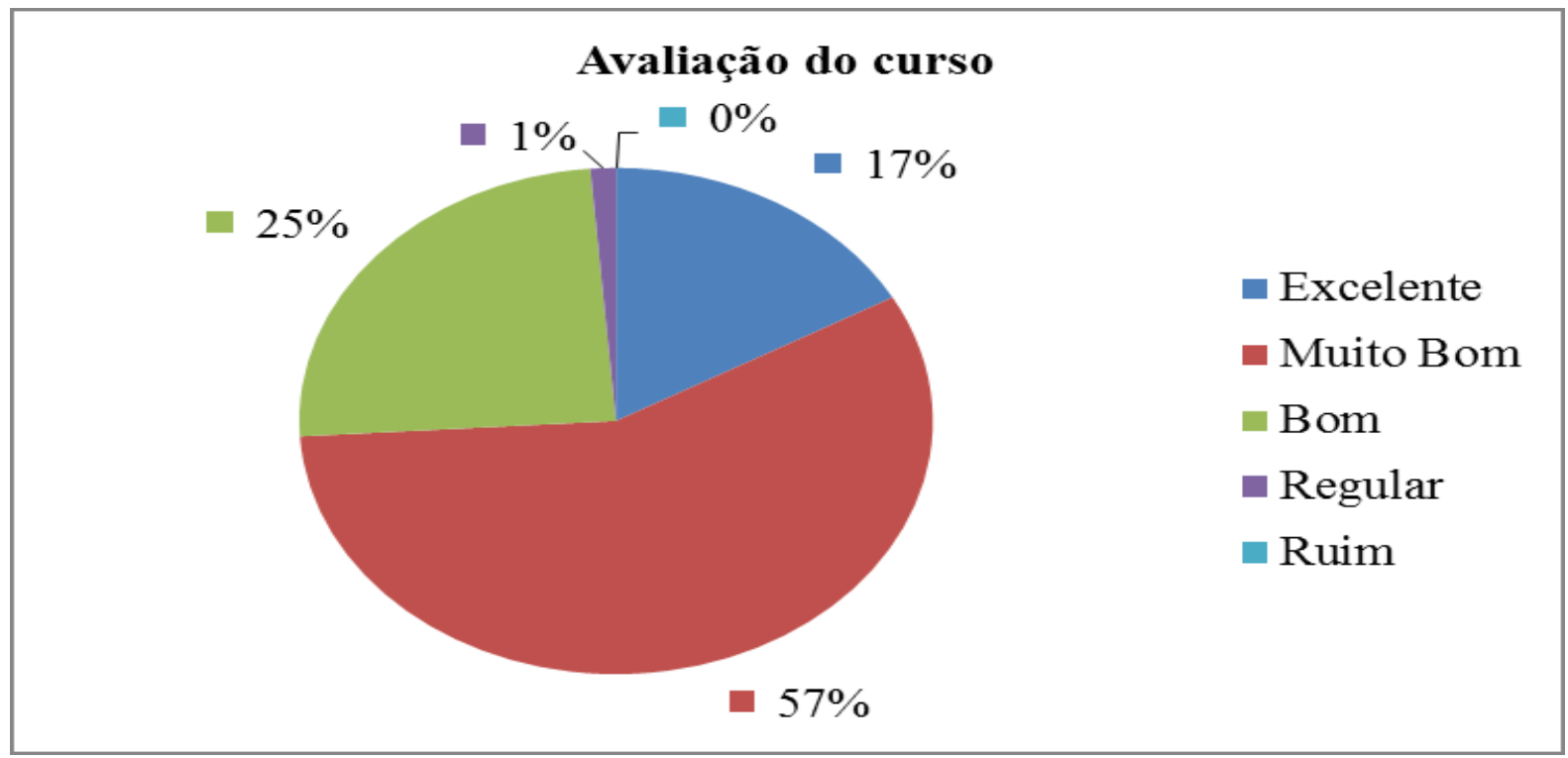

Fonte: Dados da Pesquisa 


\section{DESEMPENHO ACADÊMICO VERSUS RENDA: ANÁLISE COMPARATIVA REALIZADA COM EGRESSOS DE UM CURSO DE ADMINISTRAÇÃO \\ DOI: http://dx.doi.org/10.5007/1983-4535.2018v11n3p1}

Constata-se que o curso foi muito bem avaliado pelos alunos, sendo que $74 \%$ avaliaram o curso entre excelente e muito bom. Nenhum respondente avaliou o curso como ruim, e apenas $1 \%$ como regular e $25 \%$ dos egressos avaliaram o curso como bom.

Quando os administradores foram questionados se a formação que eles receberam na graduação é compatível com o mercado, 52\% responderam que a formação acadêmica é compatível com as demandas do mercado de trabalho, $47 \%$ que a formação é parcialmente compatível e apenas $1 \%$ que a formação não é compatível como mercado de trabalho. Estes dados são apresentados no Gráfico 5.

Gráfico 5 Formação Acadêmica x Mercado de Trabalho

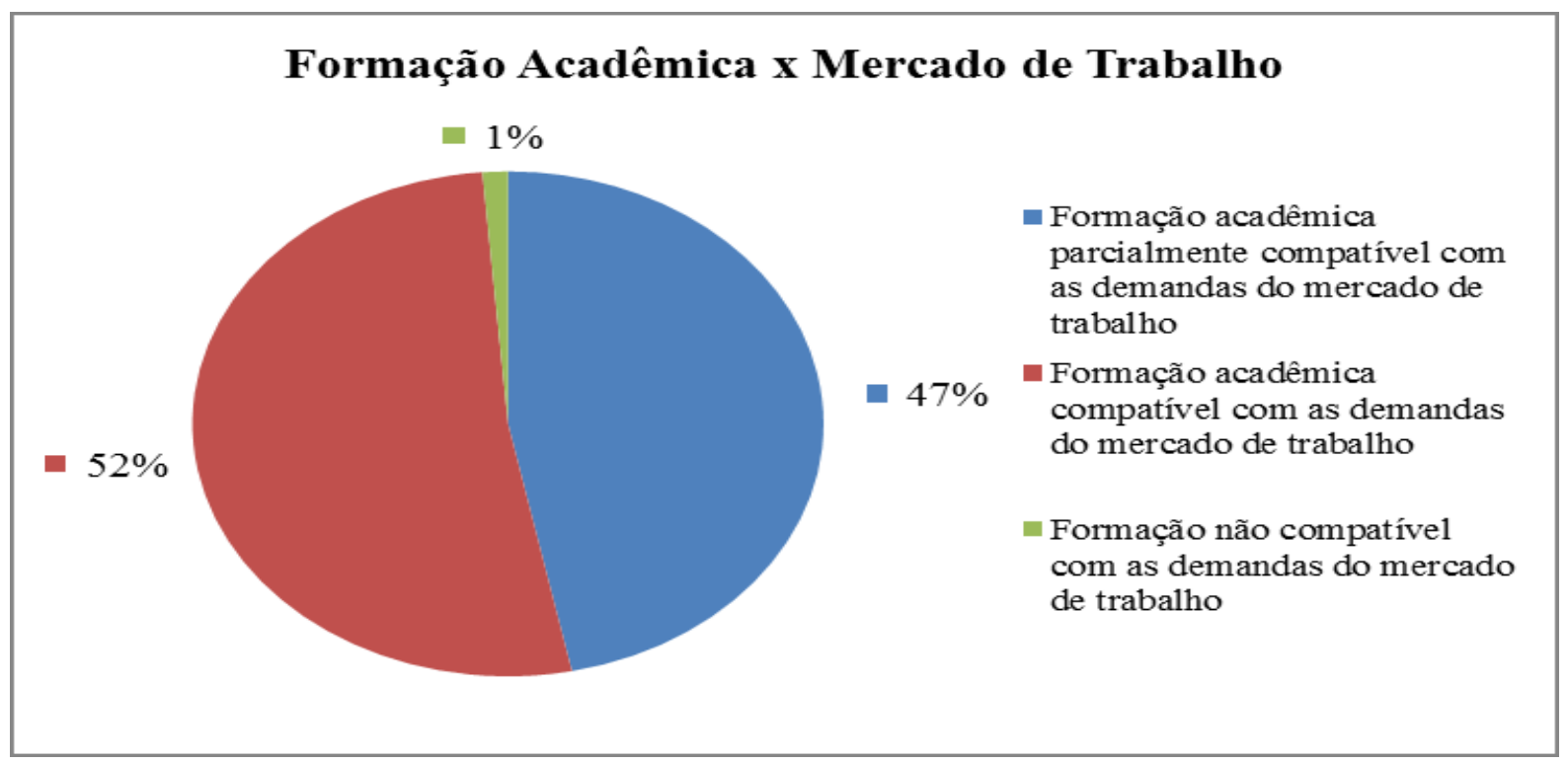

Fonte: Dados da Pesquisa

Com referência aos tipos de atividades complementares que o egresso participou no perído de graduação, houve predominância do Estágio, conforme Gráfico 6.

A grande maioria, $42 \%$ dos respondentes, relataram que fizeram estágio. Com referência à atividades complementares $13 \%$ Dos respondentes, 13\% não fizeram nenhuma das. A monitoria foi feita por $6 \%$ dos respondentes, $9 \%$ realizaram iniciação cientifica, $10 \%$ fizeram outra atividade acadêmica, 9\% empresa Junior e 11\% participou do diretório acadêmico.

Os respondentes foram questionados em qual disciplina obtiveram um melhor coeficiente de rendimento na universidade. A maioria dos respondentes obteve um rendimento melhor em Recursos Humanos, 34\%, seguida das disciplinas de Finanças, com 
26\% dos respondentes tiveram uma melhor desempenho e Produção e Logística, com 14\% dos egressos. O resultado completo desta questão é apresentado no Gráfico 7.

Gráfico 6 Atividades Complementares

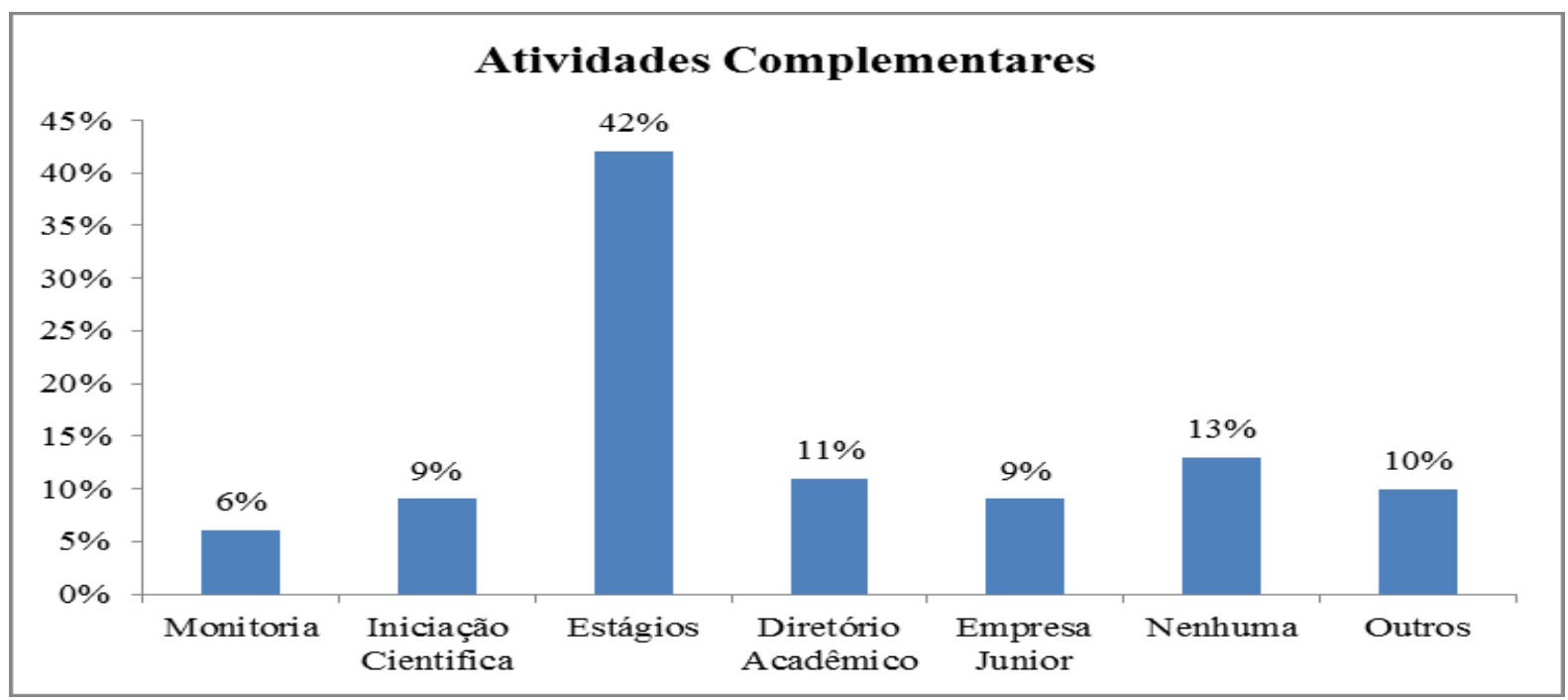

Fonte: Dados da Pesquisa

Gráfico 7 Desempenho das Disciplinas Cursadas

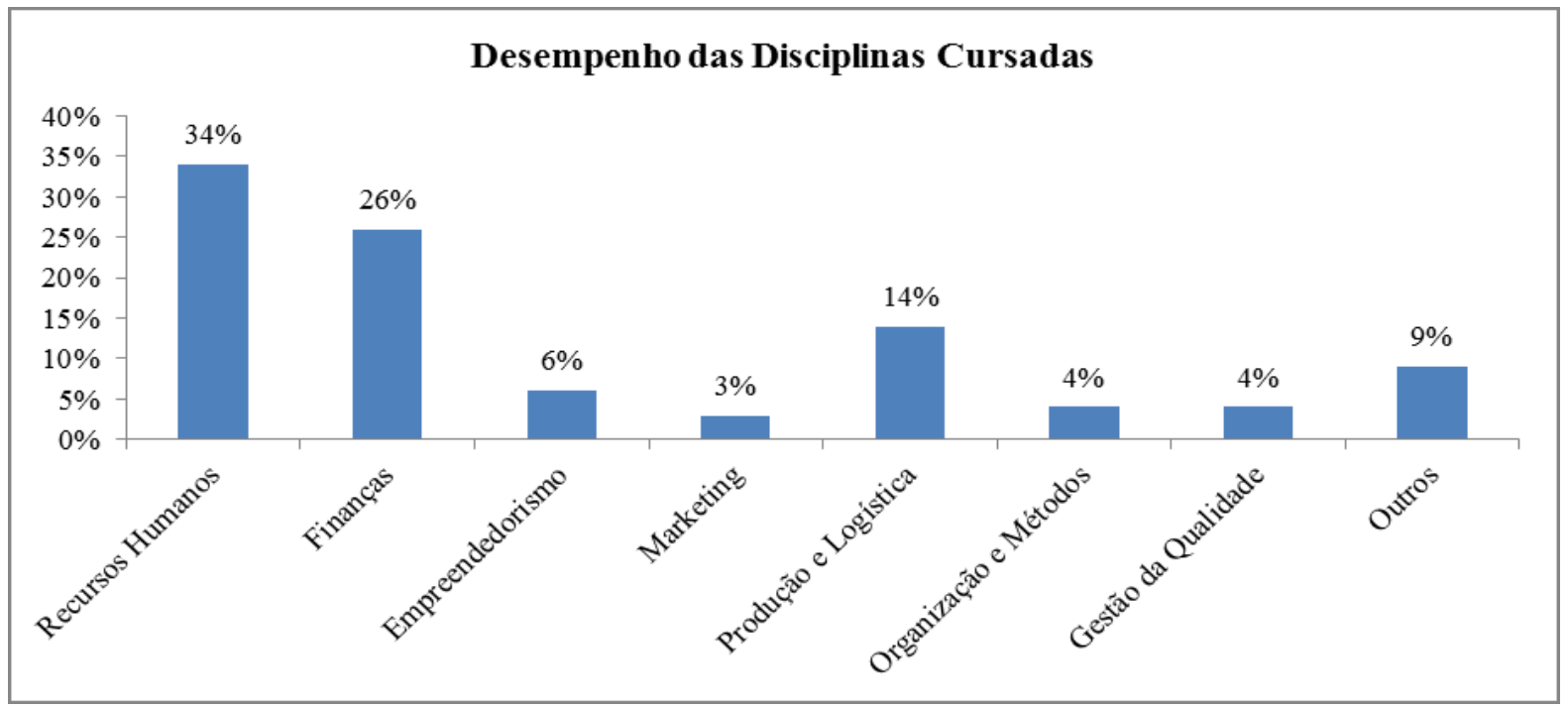

Fonte: Dados da Pesquisa

\subsection{PERFIL PROFISSIONAL DO ADMINISTRADOR}

A última parte do questionário traçou as características dos Administradores. Mais da metade dos administradores atua na sua área de formação, 62\%. Desta porcentagem, 16\% 


\section{DESEMPENHO ACADÊMICO VERSUS RENDA: ANÁLISE COMPARATIVA REALIZADA COM EGRESSOS DE UM CURSO DE ADMINISTRAÇÃO \\ DOI: http://dx.doi.org/10.5007/1983-4535.2018v11n3p1}

disseram que possuem negócio proprio, $15 \%$ atuam na área de finanças, $12 \%$ recursos humanos, nenhum dos egressos atuam na a área de Marketing, 6\% na Produção, 13\% em Logística, $4 \%$ em processos, $7 \%$ na área de vendas e $22 \%$ atuam em outras áreas na administração, conforme Gráfico 8. Verifica-se um índice significativo de egressos que possuem o seu próprio negócio.

Gráfico 8 Área de Atuação

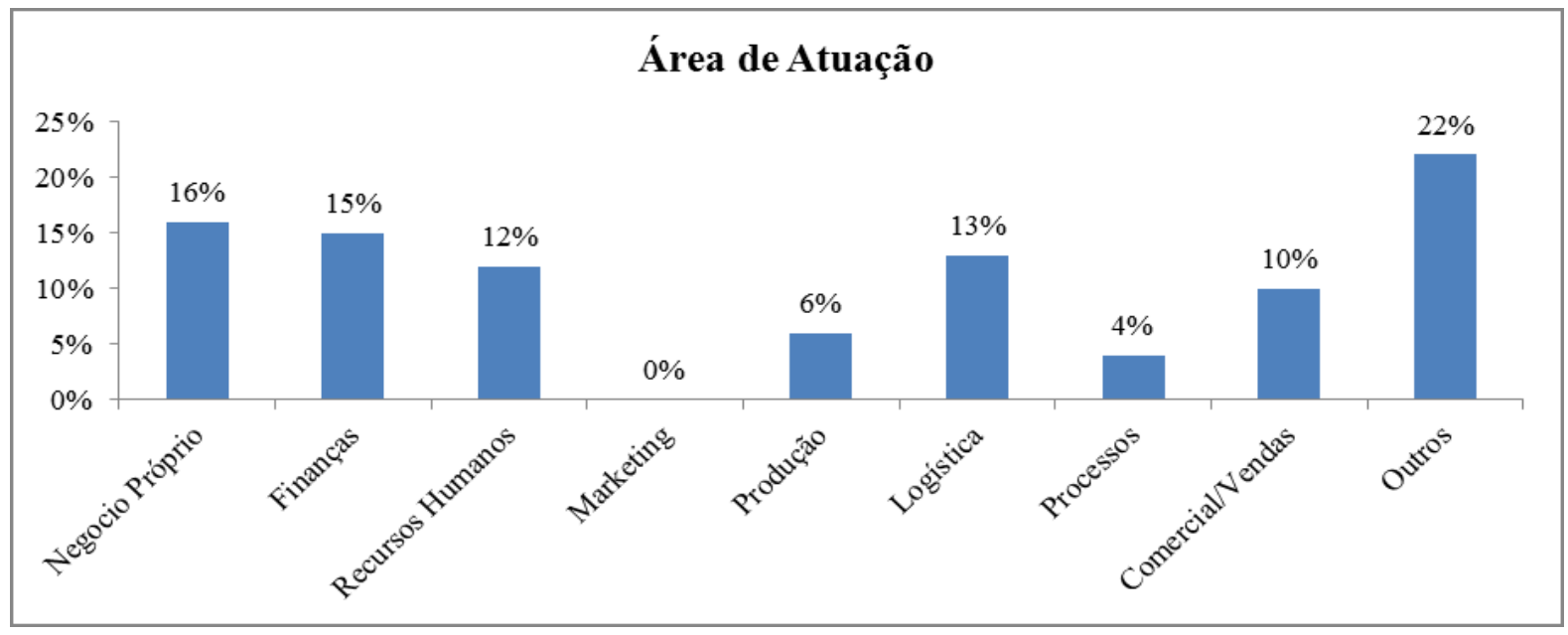

Fonte: Dados da Pesquisa

Com referência a percepção dos egressos a relação entre o desempenho nas disciplinas cursadas e seu desempenho profissional, $42 \%$ dos pesquisados considera que a relação é moderada, $40 \%$ que a relação é forte e $13 \%$ que a relação entre desempenho das disciplinas e desempenho profissional é muito forte. Apenas $1 \%$ responderam que a relação é muito fraca, $4 \%$ respondeu que a relação é fraca, conforme Gráfico 9.

Outra informação relevante é a faixa de renda dos Administradores pesquisados. A parcela mais significativa da amostra (26\%) respondeu que a sua faixa salarial é de $\mathrm{R} \$ 1.351,00$ à $\mathrm{R} \$ 2.200,00,23 \%$ recebem de $\mathrm{R} \$ 2.201,00$ a $3.500,00,14 \%$ recebem de $\mathrm{R} \$ 3.501,00$ à $\mathrm{R} \$ 5.600,00,14 \%$ recebem de $\mathrm{R} \$ 5.601,00$ até $\mathrm{R} \$ 8.900,00,18 \%$ recebem até $1.350,00$ e apenas $5 \%$ tem o renda maior que $\mathrm{R} \$ 8.900,00$. O que se percebe é a maior parte da amostra está recebendo de 2 a 5 salários mínimos. E apenas uma pequena parte tem mais que 13 salários mínimos, conforme apresentado no Gráfico 10. 


\section{DESEMPENHO ACADÊMICO VERSUS RENDA: ANÁLISE COMPARATIVA REALIZADA COM \\ EGRESSOS DE UM CURSO DE ADMINISTRAÇÃO \\ DOI: http://dx.doi.org/10.5007/1983-4535.2018v11n3p1}

Gráfico 9 Relação entre desempenho das disciplinas e Desempenho no Mercado de Trabalho

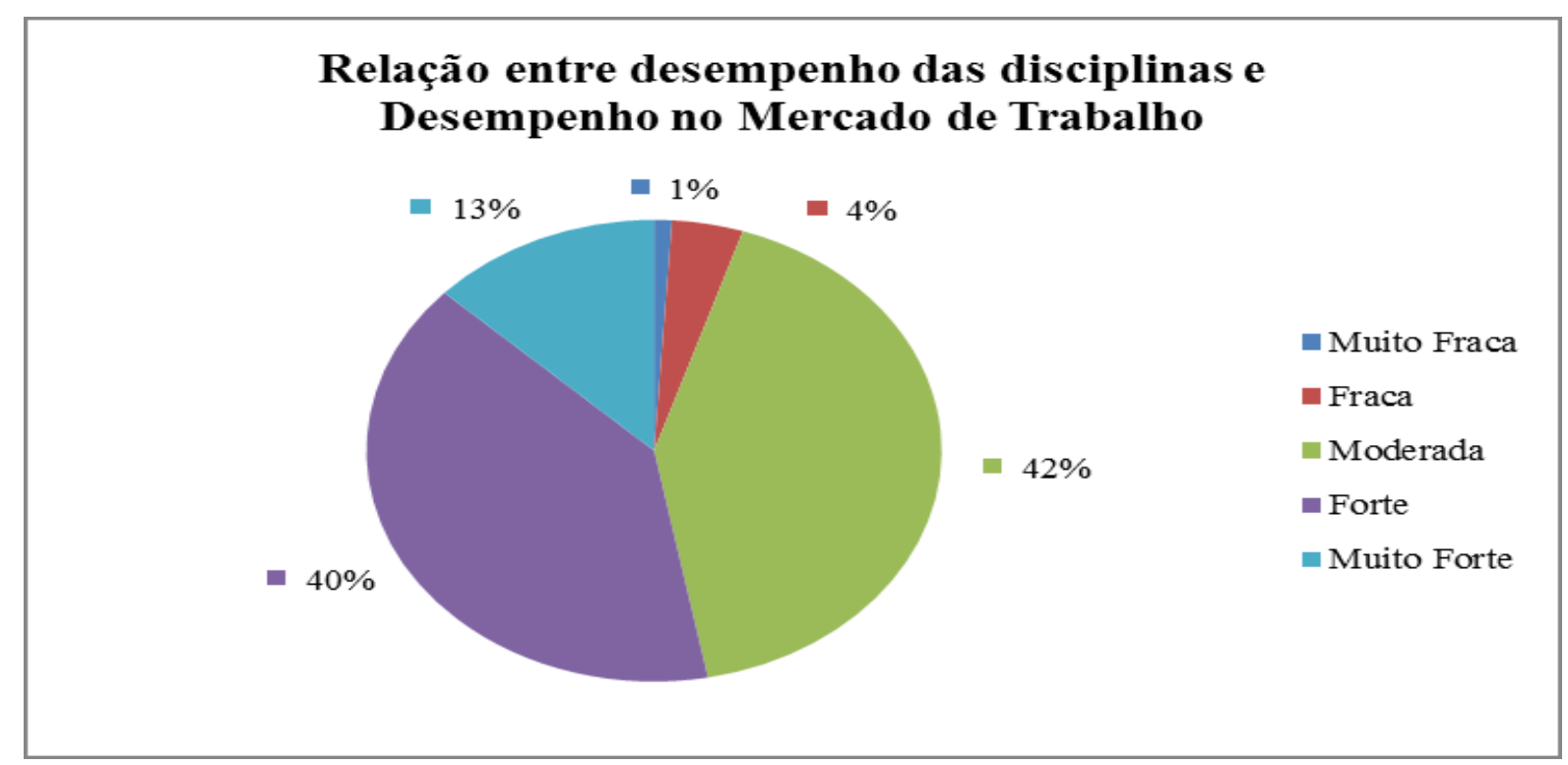

Fonte: Dados da Pesquisa

Gráfico 101 Renda

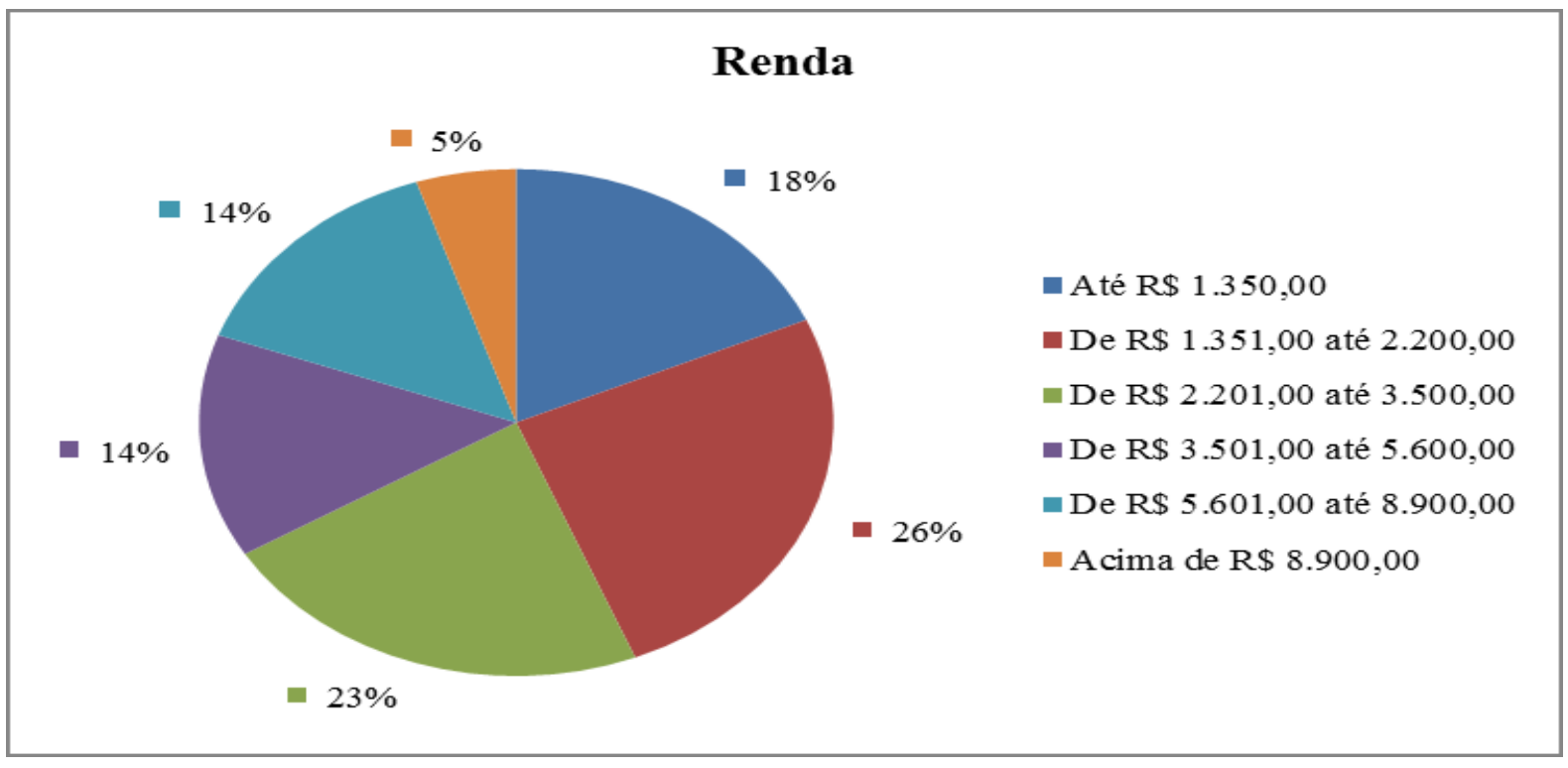

Fonte: Dados da Pesquisa

Para traçar o perfil profissional do egresso também foi perguntado se ele continuou a estudar depois que se formou e a resposta da maioria dos egressos $(86 \%)$ foi sim e apenas $14 \%$ não estudaram após a universidade.

Os egressos também especificaram os tipos de cursos que realizaram após a universidade, conforme Gráfico 11: 
Gráfico 112 Cursos realizados após a graduação de Administração

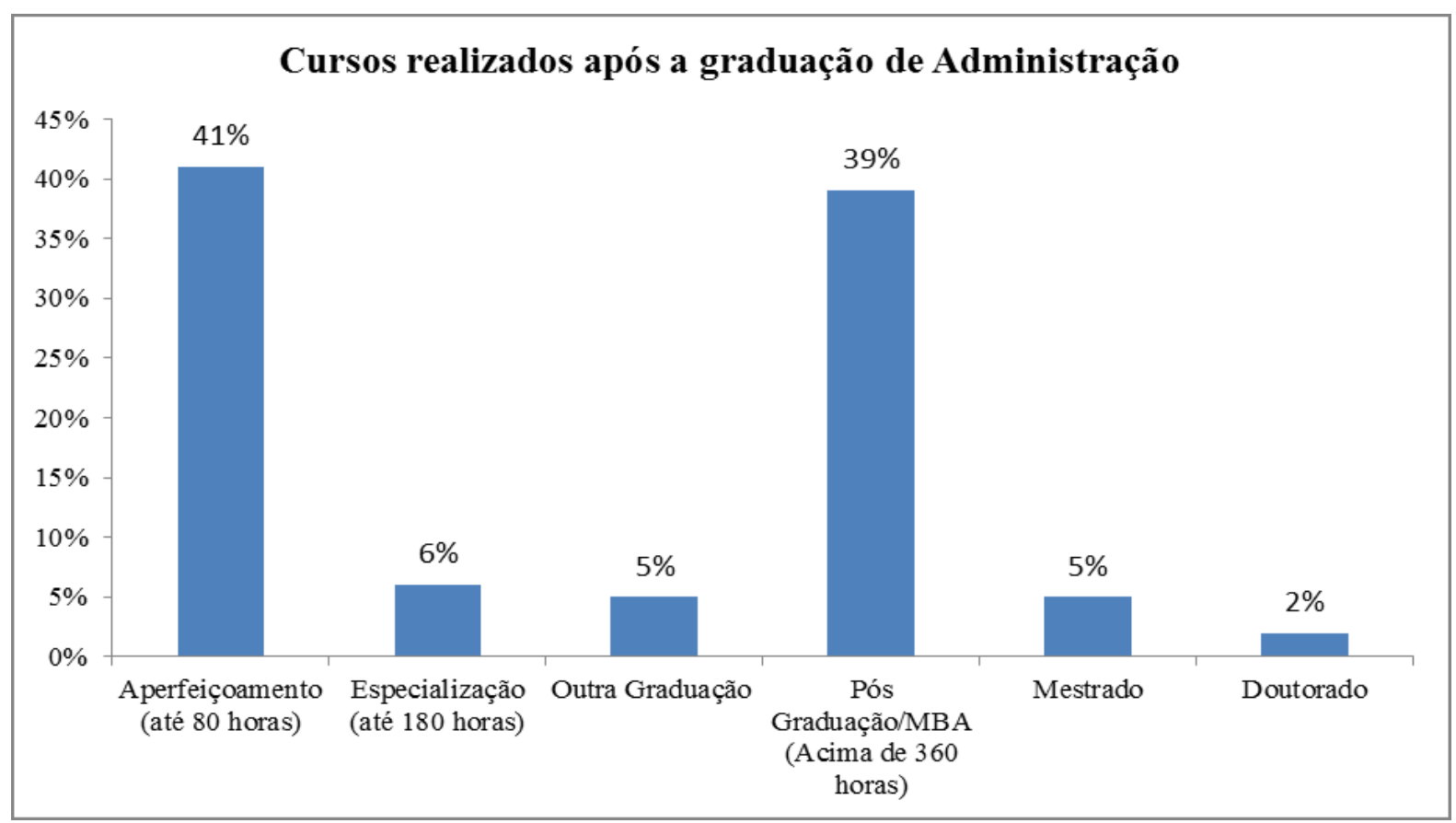

Fonte: Dados da Pesquisa

Verifica-se no Gráfico 11 que 41\% fizeram aperfeiçoamento, a pós-graduação (MBA) foi feita por $39 \%$ dos egressos, $6 \%$ fizeram especialização, outra graduação $5 \%$, mestrado $5 \%$ e $2 \%$ realizaram doutorado. Percebe-se um alto índice de participação de egressos em cursos de pós-graduação.

\subsection{CORRELAÇÃO ENTRE O DESEMPENHO ACADÊMICO COM O DESEMPENHO PROFISSIONAL}

O Gráfico 12 apresenta a correlação entre o desempenho acadêmico (Coeficiente de Rendimento) e a renda dos alunos.

Não foi possível verificar uma correlação direta entre o CR e a renda dos alunos (coeficiente de correlação igual a 0,18). Observa-se Administradores que obtiveram CRs menores que setenta e possuem renda superior a $\mathrm{R} \$ 3.500$ e por outro lado existem egressos com notas superiores a noventa que estão recebendo até $\mathrm{R} \$ 1.350,00$.

Não havendo a correlação entre CR e Renda, buscou-se analisar os dados da pesquisa sob outros aspectos. Assim, identificou-se se uma distribuição uniforme dos CRs dos alunos, com estes variando entre 66 e 92, e com alto coeficiente de correlação $(0,98)$ conforme apresentado no Gráfico 13. 
Gráfico 12 CR versus Renda

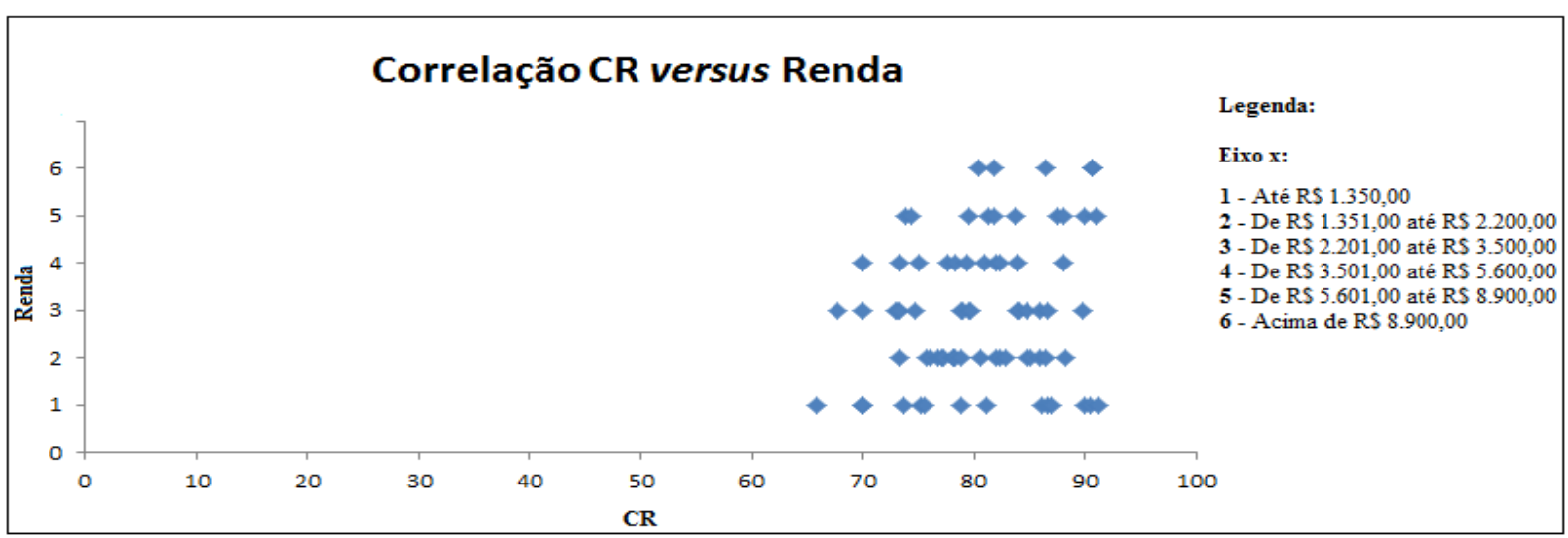

Fonte: Dados da Pesquisa

Gráfico 13 Plotagem Alunos x CRs

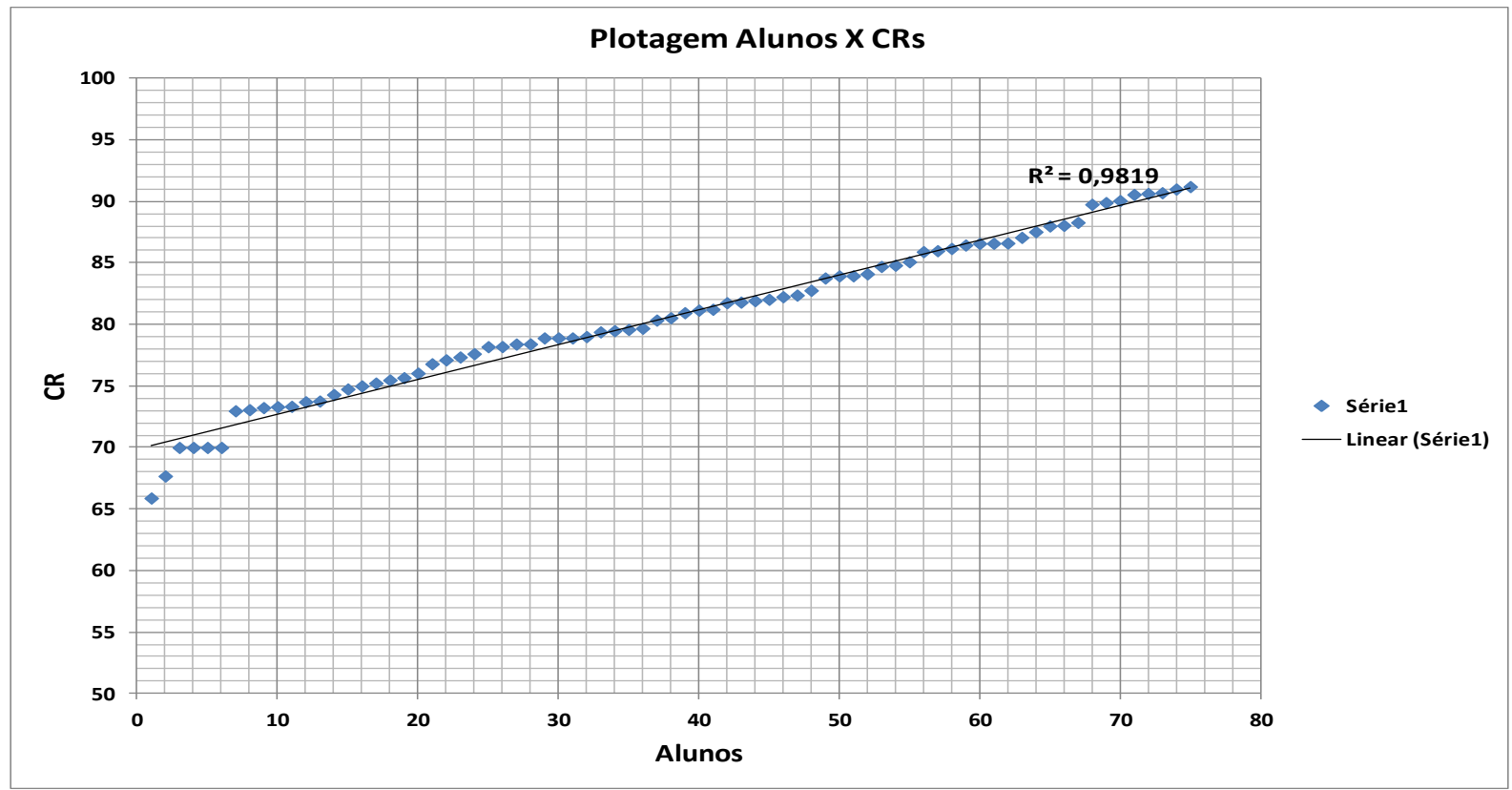

Fonte: Dados da Pesquisa

A partir desta constatação, e visando analisar os dados da pesquisa sob outra perspectiva, os alunos foram divididos em $1^{\circ}, 2^{\circ}, 3^{\circ}$ e $4^{\circ}$ quartil de acordo com os seus respectivos CRs. No $1^{\circ}$ quartil foram posicionados os egressos com os piores CRs, e no outro extremo, no $4^{\circ}$ quartil, foram posicionados os egressos com melhor desempenho acadêmico (melhores CRs). Nos $2^{\circ}$ e $3^{\circ}$ quartis foram posicionados os alunos com níveis de CRs intermediários, conforme Gráfico 14. 
Gráfico 14 Frequência de Renda de acordo com o CR

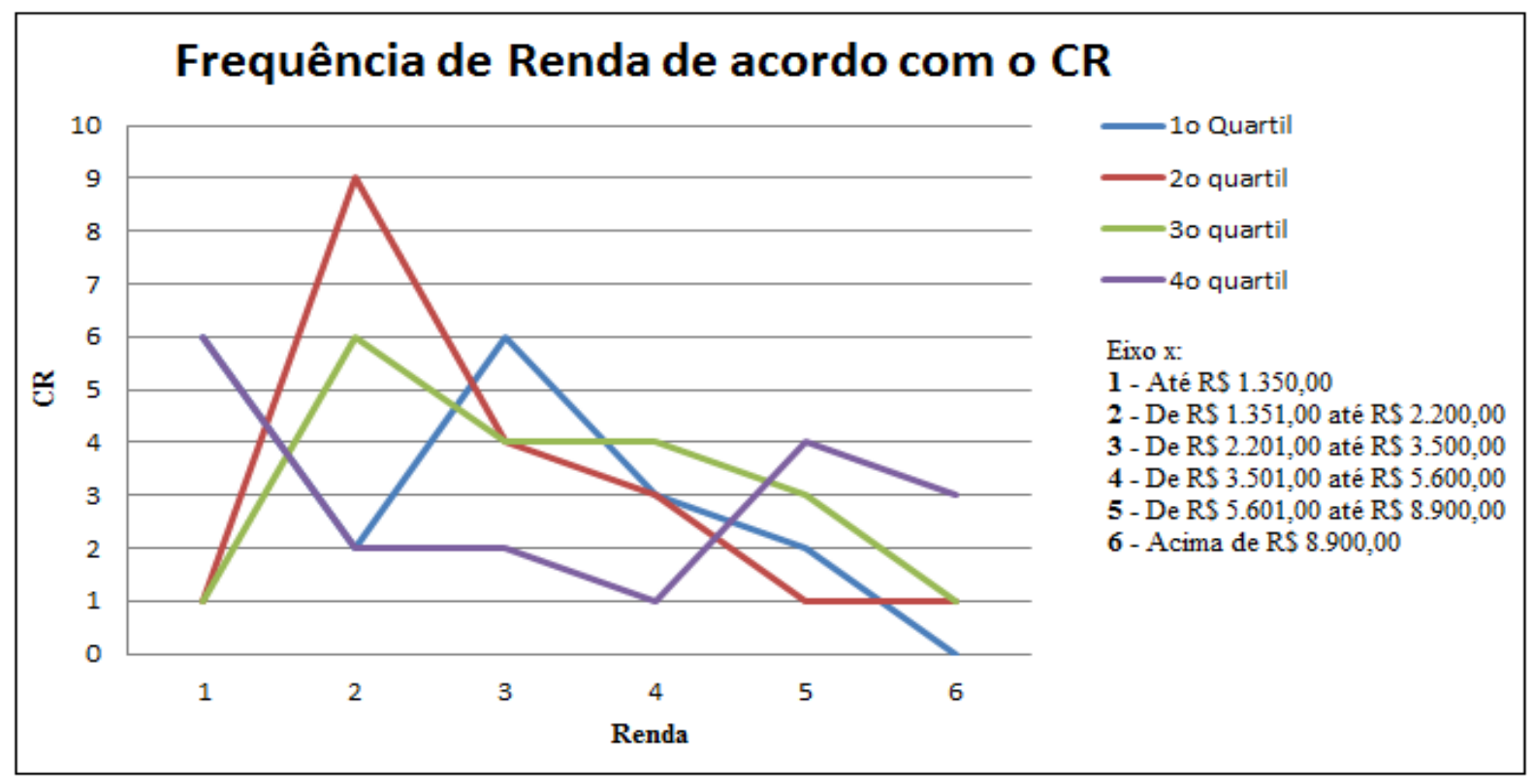

Fonte: Dados da Pesquisa

Verificou-se que $47 \%$ dos alunos que possuem renda acima de $\mathrm{R} \$ 5.601,00$ estão localizados no $4^{\circ}$ quartil (tiveram as maiores notas), seguidos dos alunos posicionados no $3^{\circ}$ quartil, com $26 \%$, sendo que os alunos posicionados no $1^{\circ}$ e $2^{\circ}$ quartil somados representam também $26 \%$ dos alunos que recebem acima de $\mathrm{R} \$ 5.601,00$.

Esta constatação corrobora os resultados da pesquisa de Ferreira e Crisóstomo (2011) que concluíram, que o desempenho acadêmico não é uma condição suficiente e necessária para o aluno ter um melhor desempenho profissional (medido pela renda), porém o aluno que obtiver melhor desempenho acadêmico (maior nota) terá maior probabilidade/possibilidade de ter o maior renda.

\section{CONSIDERAÇÕES FINAIS}

Este trabalho se mostra relevante no momento em que ele fornece um feedback a IES quanto ao ensino que a mesma está fornecendo aos alunos. Quanto a este feedback os resultados deste trabalho verificaram que os alunos pesquisados avaliam o curso de administração da faculdade pesquisada entre muito bom e excelente, ou seja, de uma forma bastante positiva. E os mesmos também acreditam que a faculdade fornece competências compatíveis, ou parcialmente compatíveis com as competências demandadas pelo mercado de trabalho. 
Esta avaliação positiva do curso de administração feita pelos alunos pesquisados pode ser verificada com o desempenho profissional dos mesmos. Já que, a grande parcela dos alunos formados $(82 \%)$ está atuando na sua área de formação.

O investimento em educação continuada foi realizado por $86 \%$ dos Administradores. Isso significa que a maior parte deles está buscando uma especialização para enfrentar as demandas do mercado.

Quanto ao objetivo de verificar se há correlação entre o desempenho acadêmico (ou Grau do Coeficiente de Rendimento) e a renda dos alunos do curso de administração, concluise que, no âmbito desta amostra, não se verificou correlação, porém quando são analisados a quais alunso recebem maior renda, foi identificado que é maior a frequência de egressos do $3^{\circ}$ e $4^{\mathrm{o}}$ quartis, que tiveram CRs maiores. Pode-se observar, que aqueles que possuem renda acima de $\mathrm{R} \$ 8.900,00$ a maior frequência está no $4^{\circ}$ quartil e é inexistente alunos que estão posicionados no $1^{\circ}$ quartil. Assim conclui-se, no âmbito desta amostra, que as notas não são suficientes para garantir maior renda, mas é um componente importante na evolução profissional do administrador. Por fim, é importante ressaltar que este resultado corrobora os achados da pesquisa realizada por Ferreira e Crisóstomo (2011) em um curso de Engenharia Metalúrgica.

\section{REFERÊNCIAS}

AMATUCCI, M. Perfil do administrador brasileiro para o século XXI: um enfoque metodológico. São Paulo: FEA/USP, 2000.

ANDRADE, R. O. B.; AMBONI, N. Gestão de Cursos de Administração: metodologia e diretrizes curriculares. São Paulo: Prentice Hall, 2004.

BAILEY, J. R.; SAPARITO, P.; KRESSEL, K.; CHRISTENSEN, E.; HOOIJBERG, R. A model for reflective pedagogy. Journal of Management Education, v. 21, 1997, p. 155-67.

BRASIL. Ministério da Educação. Resolução No. 4 de 13 julho de 2005. Dispõe sobre as Diretrizes Curriculares dos Cursos de Administração. Brasília, DF, 2005. Disponível em: $<$ http://portal.mec.gov.br/cne/arquivos/pdf/rces004_05.pdf $>$ Acesso em: 09/03/2013.

BRASIL. Ministério da Educação. Secretaria de Educação Fundamental. Parâmetros curriculares nacionais: terceiro e quarto ciclos do ensino fundamental: introdução aos parâmetros curriculares nacionais. Brasília: MEC/SEF, 1998.

CLOSS, L. Q.; ARAMBURÚ, J. V.; ANTUNES, E. D. D. Produção Científica sobre o Ensino em Administração: uma Avaliação Envolvendo o Enfoque do Paradigma da Complexidade. In: ENCONTRO ANUAL DA ASSOCIAÇÃO NACIONAL DE PÓS- 
GRADUAÇÃO EPESQUISA EM ADMINISTRAÇÃO, 30, 2006, Salvador. Anais... Salvador: ANPAD, 2006.

CNE. Conselho Nacional de Educação / Câmara de Educação Superior, Diretrizes Curriculares Nacionais do curso de graduação em Administração. Disponível em: http://portal.mec.gov.br/cne/arquivos/pdf/ces-0134.pdf Acessado em: 21.05.2013

CNE/CSE n 146/2002 (2002) Conselho Nacional de Educação / Câmara de Educação Superior, Diretrizes Curriculares Nacionais do curso de graduação em Administração. Disponível em: http://portal.mec.gov.br/cne/arquivos/pdf/ces-0134.pdf Acessado em: 21.05 .2013

FERREIRA, A.; CRISÓSTOMO, J.. A influência do desempenho acadêmico na carreira profissional: um estudo de caso em um curso de engenharia. Revista de Ensino de Engenharia, v. 30, n. 1, p. 35-44, 2011.

GIL, A. C. Como elaborar projetos de pesquisa. $4^{\text {a }}$ ed. São Paulo: Atlas, 2002. MINTZBERG, H. e LAMPEL, J. Matter of degrees: do MBAs make better CEOs? Fortune, 19 Feb. 2001.

NUNES, S. C. RAM . Revista de Administração Mackenzie, v. 10, n. 5 São Paulo, Set./Out. 2009 , p. 28-52.

SCHON, D. Educating the reflective practitioner. San Francisco : Jossey-Bass, 1987.

SCHON, D. The reflective practitioner. New York : Basic Books, 1983. 